gation. Fig. 1 depicts the results of our observations carried out on the nights of November 13, 14 and 17, 1933, between the hours 2300 and 0700 . It will be noticed that on the nights of November 13 and 14 the equivalent electron densities attained values of $3 \cdot 3 \times 10^{5}$ and $2 \cdot 2 \times 10^{5}$ respectively. The penetration frequencies for these ionic densities correspond to wave-lengths of 87 and 71.4 metres.

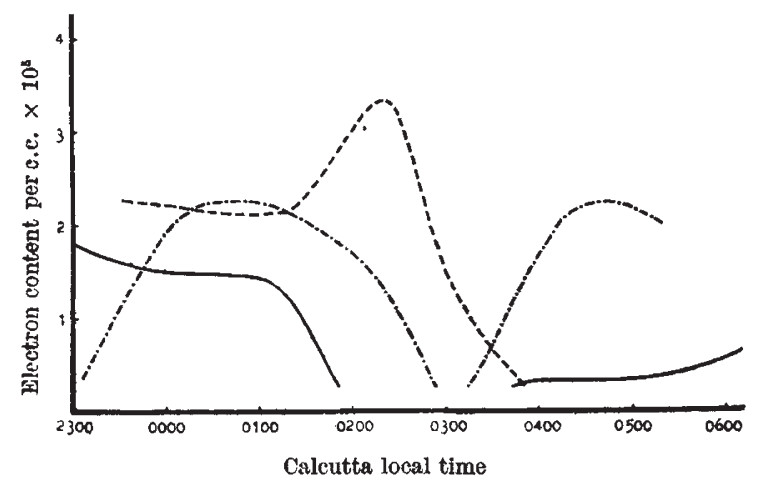

FiG. 1. Electron content of the $E$-layer during the 1933 Fia. 1. Electrid shower.

Such high densities are remarkable, because in the course of our fortnightly observations during the Polar Year 1932-33, we never recorded such densities. In fact we were never able to obtain echoes on 75 metres for our midnight observations. The high ionic density recorded, therefore, strongly suggests that the effect was due to the impact of meteors on the upper atmosphere. It should be mentioned that records kept at the Magnetic Observatory, Colaba, Bombay, and the Solar Observatory, Kodaikanal, Madras, show that no marked magnetic disturbance or solar activities occurred on these days.

S. K. Mitra.

P. SYAM.

B. N. GHose.

Wireless Laboratory,

University College of Science,

92, Upper Circular Road,

Calcutta.

Jan. 30.

1 A. M. Skellett, Proc. Inst. Radio Eng., 20, 1933 ; 1932.

2 J. P. Schafer and W. M. Goodall, Proc. Inst. Radio Eng., 20, $1941 ; 1932$.

${ }^{3}$ E. V. Appleton, Nature, 127, 197, Feb. 7, 1931.

\section{Terminal and Initial Parenchyma in Wood}

Mr. K. A. Chowdhury's remarks upon the position of the parenchyma in Terminalia tomentosa ${ }^{1}$ would seem to be applicable to other woods also. A recent examination of the wood of Cedrela odorata in this laboratory showed that the larger vessels of the early wood are partly embedded in parenchyma, some of which, judged by its position, was laid down rather earlier than these vessels. It is possible that the latest wood of a season's growth consists chiefly of parenchyma, and that the early wood of the following season is similarly constituted; but the parenchyma is sufficiently homogeneous to render this possibility improbable. Another specimen of Cedrela, probably $C$, odorata, showed that the parenchyma separated a region of rather small, fairly thick. walled fibres from another of larger, relatively thinwalled fibres; the comparatively large size and thin walls of the cells of the parenchyma in both these specimens suggest that it was laid down at the beginning of a season's growth, not at the end ; it is desirable to confirm this by studies on the living tree.

Several other Meliaceous woods were examined, but with less conclusive results. In Swietenia Mahagoni, the parenchyma appears to be terminal and not initial, and in this wood the parenchyma cells are rather small, with relatively thick walls, which would seem to confirm the view that they are laid down at the end of the growing season. In Khaya grandis and Carapa guianensis, it was not possible to decide if the parenchyma was terminal or initial.

It is well known that the vessels of the pore ring in teak (Tectona grandis) may be associated with parenchyma, and it would seem to be justifiable to refer to this as initial parenchyma.

Department of Botany,

Frank W. JANE.

University College,

London.

Feb. 18.

${ }^{1}$ Nature, 133, 215, Feb. 10, 1934.

\section{Zoospore Ciliation in the Plasmodiophorales}

Zoospores of Plasmodiophora brassicae, Woron. and Spongospora subterranea, (Wallroth) Lagerheim have been described in the literature as uniciliate. Examination of active zoospores would appear to substantiate this description. However, when preparations stained by Cotner's ${ }^{1}$ method are used, it can be shown that in addition to the long cilium, so apparent in the living zoospore, there is another which is shorter and less conspicuous. This biciliate character is illustrated by photomicrographs of zoospores of $P$. brassicce (Figs. I and 2) and S. subterranea (Figs. 3 and 4 ).

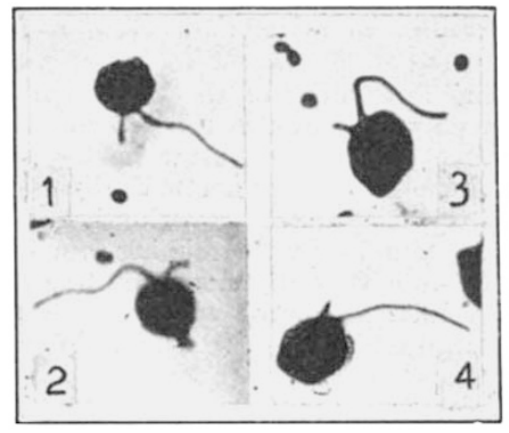

Great numbers of such zoospores were obtained by germinating, in dilute inorganic nutrient solutions, resting spores which had previously been wet, frozen and dried several times. In size and manner of swimming, these zoospores fit the descriptions given by other writers.

National Research Laboratories,

G. A. Ledingham. Ottawa, Canada.

${ }^{2}$ Bot. Gaz., 89, 295 ; 1930. 